\title{
An Optimal DASH Diet Model for People with Hypertension Using Linear Programming Approach
}

\author{
Anayo Charles Iwuji ${ }^{1}$, Mercy Nnanna ${ }^{1}$, Nonso Ifeyinwa Chizube Ndulue ${ }^{2}$ \\ ${ }^{1}$ Department of Statistics, Michael Okpara University of Agriculture, Umudike, Nigeria \\ ${ }^{2}$ Department of Nutrition and Dietetics, Michael Okpara University of Agriculture, Umudike, Nigeria \\ Email: charlywonders@yahoo.com,ifeyinwachizube@yahoo.com
}

Received 6 December 2015; accepted 1 March 2016; published 4 March 2016

Copyright @ 2016 by authors and Scientific Research Publishing Inc.

This work is licensed under the Creative Commons Attribution International License (CC BY). http://creativecommons.org/licenses/by/4.0/

c) (†) Open Access

\section{Abstract}

Selecting diets by quantitative techniques is becoming increasingly common. Linear programming is the most popular technique for the selection of least cost mixes of food to meet specific nutritional requirements for a particular group of persons for either general health or disease-related reason. Hypertension is a silent killer and its prevalence rate especially in the developing countries, which has been mostly associated to demographic, environmental and genetic factors, is becoming alarming. The DASH diet has been clinically proven to prevent and control hypertension. In this paper, a model that provides a Daily Optimal (minimum cost) DASH Diet plan for people with hypertension is formulated. The objective is to obtain daily minimum cost diet plans that satisfy the DASH Diets' nutrients Tolerable Upper and Lower Intake for different daily Calorie Levels. The formulated DASH diet model was further illustrated using real data set with food samples gotten from the DASH eating plan chart. A DASH diet model for a hypertensive person with a 2000daily-caloric need was formulated and its optimal diet plan for a day obtained with a total cost of 944.41 Naira. Optimal diet plans for other recommended daily calorie levels were also obtained.

\section{Keywords}

DASH (Dietary Approaches to Stop Hypertension), Hypertension, Minimum Cost Diet Plan, Linear Programming Diet Problem

\section{Introduction}

The "diet problem" is a classical example of the application of linear programming method. The solution of the 
diet problem is simply getting a list of foods that collectively provide some selected required nutrients in specified minimal quantities given certain constraints. So we try to minimize the cost while guaranteeing certain and predetermined nutritional value. This linear programming diet problem has been applied for certain group of people for either general health or disease-related reasons. One of the diseases that particularly need strict diet adherence for the survival of the patient is hypertension. Environmental factors have been mainly associated as the cause of hypertension. [1] Stevens et al. (2000) studied the association between ethnicity and hypertension in high-income countries and found out that there is a higher prevalence of hypertension in black ethnic groups compared to white ethnic groups. [2] Seedat et al. (2000) in their study concluded that urbanization is a key reason for the increasing rates of hypertension, as evident in the higher prevalence of hypertension in urban areas. [3] Addo et al. (2007) in their research work concluded that urban lifestyle characterized by sedentary living, increase of salt intake, obesity and stress contributes to hypertension. A substantial body of evidence strongly supports the concept that multiple dietary factors affect blood pressure. In 1992 scientist supported by the U.S.-based National Heart, Lung, and Blood Institute worked with five of the most well-respected medical research centers in different cities across the U.S. to conduct the largest and most detailed research study. They conducted two key researches with the purpose of testing the effects of dietary patterns on blood pressure. They were called the "DASH" for Dietary Approaches to Stop Hypertension. The DASH trial showed that dietary patterns can and do affect blood pressure (systolic $<180 \mathrm{mmHg} \&$ diastolic of 80 to $95 \mathrm{mmHg}$ ). Its findings showed that blood pressures were reduced with an eating plan that is low in saturated fat, cholesterol and total fat and that also has less salt and sodium. [4] U.S. National Heart, Lung and Blood Institute (December, 2006) in the "guide to lowering your blood Pressure with DASH" presented the DASH diet which is made up of fruits, vegetables, and low-fat dairy foods together with whole grains products, fish, poultry, and nuts.

The diet problem has been used in various areas of human dietetics with the objective of obtaining a least cost diet plan for general health or disease-related conditions. [5] Stigler (1945) obtained the least cost of feeding a moderately active man weighing 154 pounds. Even though he did not actually use linear programming, he determined how much of each 77 foods should be eaten on a daily basis so that the man's intake of nine nutrients (including calories) will be at least equal to the recommended dietary allowance (RDA's) suggested by the national research council in 1943 with the cost of the diet being minimal. [6] Smith (1959) formulated a linear programming diet model that is used to select quantities of food that meets nutritional and conventional specifications at least cost. The model was given as

$$
\begin{gathered}
\sum P_{j} \lambda_{j}(j=1,2, \cdots, n) \\
\text { subject to } \sum a_{i j} \lambda(\leq, \geq) b \\
\text { and } \lambda_{j} \geq 0(i=1,2, \cdots, m) .
\end{gathered}
$$

[7] Fletcher et al. (1994) in their work discussed the use of mathematical modeling in presenting the relationship between acceptable diets and satisfactory nutrition. They deviated from the normal "diet problem" methodology where the objective function is to attain the minimum cost of the diet plan and used a different approach where the objective function is based on the food preferences of individuals. They described the use of linear programming in constructing individually acceptable clinically appropriate diet. [8] Mamat et al. (2012) presented a balance diet planning for eating disorders and disease-related lifestyle but used fuzzy linear programming approach. They actualized a balance diet plan that enabled each user to take a variety of foods for a few times per day to enable them obtain nutritional requirements for their body's daily routine and to help prevent chronic diseases such as heart attack and diabetes.

In this paper we present the DASH diet plan as a reliable dietary approach for controlling the systolic high blood pressure problem especially to the hypertensive in developing countries. We then formulate a DASH diet model that gives a minimum cost daily diet plan that meets the nutritional requirements for reducing high blood pressure for different recommended daily calorie levels using the linear programming approach.

\section{Methodology}

\subsection{Linear Programming Diet Model}

The diet problem in linear programming is basically to minimize the cost of the diet and ensure by way of the constraints that some nutritional constraints are satisfied. The first solution to the diet problem using linear pro- 
gramming was done by Smith. The general structure of these problems is given as follows.

$$
\text { Min } Z=C_{1} X_{1}+C_{2} X_{2}+C_{3} X_{3}+\cdots+C_{n} X_{n}
$$

Subject to the constraints

$$
\begin{gathered}
a_{11} X_{1}+a_{12} X_{2}+a_{13} X_{3}+\cdots+a_{1 n} X_{n}(\leq, \geq) b_{1} \\
a_{21} X_{1}+a_{22} X_{2}+a_{23} X_{3}+\cdots+a_{2 n} X_{n}(\leq, \geq) b_{2} \\
a_{31} X_{1}+a_{32} X_{2}+a_{33} X_{3}+\cdots+a_{3 n} X_{n}(\leq, \geq) b_{3} \\
a_{m 1} X_{1}+a_{m 2} X_{2}+a_{m 3} X_{3}+\cdots+a_{m n} X_{n}(\leq, \geq) b_{m} \\
\text { and } x_{1}, x_{2}, x_{3}, \cdots, x_{n} \geq 0
\end{gathered}
$$

where $m$ is the number of nutrients;

$n$ is the number of food items;

$a_{i j}$ is the number of units of nutrients $i$ one unit of food item $j$;

$b_{i}$ is the specific number of units of nutrient $i$ required;

$C_{j}$ is the cost of food item $j$;

$X_{j}$ is the number of units of food item $j$ in the solution.

$i=1,2,3, \cdots, n$ and $j=1,2,3, \cdots, m$.

\subsection{Formulation of the DASH Diet Model}

Step 1: Decision variables.

The decision variables for the DASH diet model are $X_{1}, X_{2}, X_{3}, \cdots, X_{n}$ which represents the daily number of servings of foods $1,2,3, \cdots, n$.

Step 2: Objective Function.

The objective of the model is to minimize the diet cost.

Let the cost of a serving of each food item be given as $C_{1}, C_{2}, C_{3}, \cdots, C_{n}$. Since the objective function has to be linear in the decision variables, the objective function is given as

$$
\text { Minimize } D C=C_{1} X_{1}+C_{2} X_{2}+C_{3} X_{3}+\cdots+C_{n} X_{n}
$$

where $D C=$ Diet Cost.

Step 3: Constraints.

The constraints of the model are on the satisfaction of the DASH calorie level nutrient requirement. The parameters of the left hand side function constraints are the nutrient content of the foods with respect to the "DASH concerned" nutrients. The DASH is concern mainly on the nutrients that according to the DASH research findings are to be taken less (Sodium, Saturated fat, Total fat, Cholesterol) and those that are to be taken more (Magnesium, Potassium, Calcium, Fiber) to reduce high blood pressure. So the constraints are as follows

$$
a_{11} X_{1}+a_{12} X_{2}+a_{13} X_{3}+\cdots+a_{1 n} X_{n} \leq R_{1 c}
$$

(constraint on total fat)

$$
a_{21} X_{1}+a_{22} X_{2}+a_{23} X_{3}+\cdots+a_{2 n} X_{n} \leq R_{2 c}
$$

(constraint on sodium)

$$
a_{31} X_{1}+a_{32} X_{2}+a_{33} X_{3}+\cdots+a_{3 n} X_{n} \leq R_{3 c}
$$

(constraint on cholesterol)

$$
a_{41} X_{1}+a_{42} X_{2}+a_{43} X_{3}+\cdots+a_{4 n} X_{n} \leq R_{4 c}
$$

(constraint on saturated fat)

$$
a_{51} X_{1}+a_{52} X_{2}+a_{53} X_{3}+\cdots+a_{5 n} X_{n} \geq R_{5 c}
$$

(constraint on calcium) 
(constraint on magnesium)

$$
a_{61} X_{1}+a_{62} X_{2}+a_{63} X_{3}+\cdots+a_{6 n} X_{n} \geq R_{6 c}
$$

$$
a_{71} X_{1}+a_{72} X_{2}+a_{73} X_{3}+\cdots+a_{7 n} X_{n} \geq R_{7 c}
$$

(constraint on fibre)

(constraint on potassium)

$$
a_{81} X_{1}+a_{82} X_{2}+a_{83} X_{3}+\cdots+a_{8 n} X_{n} \geq R_{8 c}
$$

$$
a_{91} X_{1}+a_{92} X_{2}+a_{93} X_{3}+\cdots+a_{9 n} X_{n}=R_{c}
$$

(constraint on calorie)

$$
\begin{aligned}
& X_{j} \geq S_{L j c} \\
& X_{j} \leq S_{H j c}
\end{aligned}
$$

where

$$
X_{1}, X_{2}, X_{3}, \cdots, X_{n} \geq 0,
$$

$j=1,2,3, \cdots, n$, where $j$ is number of food items.

$i=1,2,3, \cdots, 9$, where $i$ is number of nutrients.

For the parameters;

$a_{11}, a_{12}, a_{13}, \cdots, a_{8 n}$ are the content of the "DASH nutrients" in the foods.

$R_{1 c}, R_{2 c}, R_{3 c}$ and $R_{4 c}$ are the Tolerable Upper Intake Level for Total fat, Sodium Cholesterol and Saturated fat respectively for calorie level $c$.

$R_{5 c}, R_{6 c}, R_{7 c}$ and $R_{8 c}$ are the Tolerable Lower Intake Level for Calcium, Magnesium, Fiber and Potassium respectively for calorie level $c$.

$R_{c}$ is the calorie level.

$S_{L j c}$ is the estimated least number of daily servings of food item $j$ for calorie level $c$.

$S_{H j c}$ is the estimated highest number of daily servings of food item $j$ for calorie level $c$.

\subsection{Data Illustration of the DASH Diet Model}

The formulated DASH diet model will be illustrated using real data set. The Optimal DASH Diet plan for a day for an individual with a 2000-caloric need, which is a recommended calorie need for male and female persons of certain age groups and level of activity as shown in Table A2, will be considered in the illustration. 8 sample foods were randomly chosen from the different food groups (namely grains, vegetables, fruits, low-fat milk products, fish and nuts) in the DASH eating plan chart as given in the "guide to lowering your blood Pressure with DASH" for the illustration. (Note that individuals that intend to use this model can use their preferred foods for each day to obtain that days' Optimal diet plan). The prices of the foods (in Naira) were collected from Ubani central market, Umuahia, Abia State, Nigeria in May 2015. The nutritional content of the foods used in this work were obtained from the West African food composition table compiled by Food and Agricultural Organization of the United Nations in collaboration with the International network of Foods Data Systems (INFOODS), the West African Health Organization (WAHO) and Bioversity International. The serving sizes of the foods (in grams) were measured in the Nutrition and Dietetics Laboratory of Michael Okpara University of Agriculture Umudike, Abia State, Nigeria. The Tolerable Upper and Lower Intake Level of the nutrients is based on the nutrients level of a sample menu for 2000 calorie a day DASH eating plan also given in the "guide to lowering your blood Pressure with DASH". To obtain the optimal diet plan for a day, we enter the cost per servings of the foods and their nutrient content together with the Tolerable Upper and Lower Intake level of the nutrients and the estimated least and highest number of servings of foods into the formulated DASH diet model (10) to (22). This gives the formulated Dash diet model for 2000 calories a day in (23) to (46). The optimal diet plan obtained is presented in Table 1.

The optimal diet plan for a day in Table 1 shows the serving sizes of each food contained in the optimal plan and its cost.

The expected nutrient composition with respect to the Lower and Upper Tolerable Intake Level of the nutrients is compared to the actual nutrient composition in the optimal diet plan as shown in Table 2. 
Table 1. Optimal daily diet plan for 2000 calories a day.

\begin{tabular}{ccc}
\hline Foods & Daily serving sizes & Cost of servings (Naira) \\
\hline Carrot (cut up) & 20.00 & N300.00 \\
Groundnut (boiled, without salt) & 0.39 & N7.87 \\
Bread (whole wheat) & 3.54 & N53.04 \\
Sweet potato (boiled, without salt) & 4.00 & N60.00 \\
Milk (low fat, skimmed) & 9.00 & N270.00 \\
Orange & 6.99 & N104.85 \\
Watermelon & 9.00 & N135 \\
Fish (grilled, without salt) & 0.27 & N13.65 \\
Optimal daily diet cost & & N944.41 \\
\hline
\end{tabular}

Table 2. Comparison of expected and actual nutrient composition of diet plan.

\begin{tabular}{ccc}
\hline Nutrients & Lower and upper tolerable intake level & Actual quantity in optimal solution \\
\hline Total fat & $\leq 68 \mathrm{~g}$ & $24.80 \mathrm{~g}$ \\
Sodium & $\leq 1500 \mathrm{mg}$ & $1220.8 \mathrm{mg}$ \\
Cholesterol & $\leq 129 \mathrm{mg}$ & $27 \mathrm{mg}$ \\
Saturated fat & $\leq 16 \mathrm{mg}$ & $7.55 \mathrm{mg}$ \\
Calcium & $\geq 1334 \mathrm{mg}$ & $1334.2 \mathrm{mg}$ \\
Magnesium & $\geq 542 \mathrm{mg}$ & $542.8 \mathrm{mg}$ \\
Fiber & $\geq 34 \mathrm{mg}$ & $90.74 \mathrm{mg}$ \\
Potassium & $\geq 4721 \mathrm{mg}$ & $8502.2 \mathrm{mg}$ \\
Calorie & $=2000$ & 2000.2 calories \\
\hline
\end{tabular}

The comparison in Table 2 shows that the Optimal daily diet plan meets the DASH Lower and Upper Tolerable Intake Level of the nutrients as the actual quantities in the optimal diet plan are either less or higher than the Lower and Upper Tolerable Intake Level respectively.

The illustration as mentioned earlier is for those who due to their age, level of activity and weight are recommended to take an eating plan of about 2000 calories a day. For those allowed to take the other daily calorie levels as shown in Table 2, the modification will only be to put the appropriate Calorie level value, $R_{c}$, in (19) in the formulated DASH diet model in obtaining the optimal daily diet plan for that calorie level. The estimated Least number of daily servings of food item $j$ for calorie level $c\left(S_{L j c}\right)$ in (20) and the estimated highest number of daily servings of food item $j$ for calorie level $c\left(S_{H j c}\right)$ in (21) in the formulated DASH diet model can also be adjusted.

To portray this, replacing the Calorie level value, $R_{c}$, in (32) in the formulated DASH diet model (23) to (46) for the 2000 calories a day model gives the Optimal daily diet plans for the calorie levels 2200, 2400, 2600 and 2800 as shown in Table 3. Also replacing $R_{c}$ and adjusting $S_{H j c}$ and $S_{L j c}$ also gives the optimal daily diet plan for 1800 and 3000 calorie levels.

\section{Conclusion}

The DASH diet model that minimizes the daily cost of the DASH eating plan has been formulated following the mathematical model of the linear programming "diet problem" and was further illustrated using some chosen sample foods from the DASH food chart to formulate 2000 calories a day mathematical model used in obtaining a minimum cost eating plan. The optimal diet plan for different daily calorie levels was also given. But it should be noted that even though the primary objective of the model is to minimize daily diet cost, if an individual is not comfortable with the mix of foods in the outcome of an optimal eating plan obtained or if a particular solution fails to produce a basic feasible solution, modifications can be made in the solution by replacing some foods 
Table 3. Optimal diet plan for a day for different calorie levels.

\begin{tabular}{|c|c|c|c|c|c|c|}
\hline \multirow[b]{2}{*}{ Food items } & \multicolumn{2}{|c|}{1800 calories daily } & \multicolumn{2}{|c|}{2200 Calories daily } & \multicolumn{2}{|c|}{2400 calories daily } \\
\hline & $\begin{array}{l}\text { Daily serving } \\
\text { sizes }\end{array}$ & $\begin{array}{l}\text { Cost of servings } \\
\text { (Naira) }\end{array}$ & $\begin{array}{l}\text { Daily serving } \\
\text { sizes }\end{array}$ & $\begin{array}{l}\text { Cost of servings } \\
\text { (Naira) }\end{array}$ & $\begin{array}{l}\text { Daily serving } \\
\text { sizes }\end{array}$ & $\begin{array}{l}\text { Cost of servings } \\
\text { (Naira) }\end{array}$ \\
\hline Carrot & 20.00 & 300.00 & 20.00 & 300.00 & 20.00 & 300.00 \\
\hline Groundnut & 1.00 & 20.00 & 0 & 0 & 0.93 & 18.70 \\
\hline Bread & 4.00 & 60.00 & 4.89 & 73.32 & 4.80 & 71.98 \\
\hline Sweet potato & 10.53 & 157.00 & 5.15 & 77.26 & 6.00 & 90.00 \\
\hline Milk & 10.00 & 300.00 & 9.00 & 270.00 & 9.00 & 270.00 \\
\hline Orange & 4.39 & 65.79 & 8.00 & 120.00 & 8.00 & 120.00 \\
\hline Watermelon & 0.07 & 1.12 & 9.00 & 135.00 & 9.00 & 135.00 \\
\hline Fish & $0 . .00$ & 0.00 & 0.28 & 14.15 & 0.24 & 12.05 \\
\hline \multirow[t]{2}{*}{ Total cost } & & 903.91 & & 919.73 & & 1017.73 \\
\hline & \multicolumn{2}{|c|}{2600 calories daily } & \multicolumn{2}{|c|}{2800 calories daily } & \multicolumn{2}{|c|}{3000 calories daily } \\
\hline Food items & $\begin{array}{l}\text { Daily serving } \\
\text { sizes }\end{array}$ & $\begin{array}{l}\text { Cost of servings } \\
\text { (Naira) }\end{array}$ & $\begin{array}{l}\text { Daily serving } \\
\text { sizes }\end{array}$ & $\begin{array}{l}\text { Cost of servings } \\
\text { (Naira) }\end{array}$ & $\begin{array}{l}\text { Daily serving } \\
\text { sizes }\end{array}$ & $\begin{array}{l}\text { Cost of servings } \\
\text { (Naira) }\end{array}$ \\
\hline Carrot & 20.00 & 300.00 & 20.00 & 300.00 & 20.00 & 300.00 \\
\hline Groundnut & 2.38 & 47.59 & 3.82 & 76.47 & 1.00 & 20.00 \\
\hline Bread & 4.82 & 72.30 & 4.84 & 72.62 & 4.70 & 70.49 \\
\hline Sweet potato & 6.00 & 90.00 & 6.00 & 90.00 & 4.00 & 60.00 \\
\hline Milk & 9.00 & 270.00 & 9.00 & 270.00 & 10.00 & 300.00 \\
\hline Orange & 8.00 & 120.00 & 8.00 & 120.00 & 18.41 & 276.09 \\
\hline Watermelon & 9.00 & 135.00 & 9.00 & 135.00 & 10.00 & 150.00 \\
\hline Fish & 0.17 & 8.75 & 0.11 & 5.45 & 0.22 & 11.04 \\
\hline Total cost & & 1043.64 & & 1069.54 & & 1187.62 \\
\hline
\end{tabular}

in the solution with others and redoing the optimization or by making "as small a change as possible" in the estimated daily number of servings of the foods in consultation with of dietician.

\section{References}

[1] Stevens, J., Thomas, N., Schreiner, P. and Folsom, A.R. (2000) Association of Black Groups, Fat Distribution and Obesity with Hypertension in a Bi-Ethnic Population: The ARIC Studies. Obesity Research, 8, 516-524. http://dx.doi.org/10.1038/oby.2000.64

[2] Seedat, V.K. (2000) Hypertension in Developing Nations in Sub-Saharan African. Journal of Human Hypertension, 14, 739-747. http://dx.doi.org/10.1038/sj.jhh.1001059

[3] Addo, J., Smeeth, L. and Leon, D.A. (2007) Hypertension in Sub-Saharan Africa: A Systematic Review. Hypertension, 50, 1012-1018. http://dx.doi.org/10.1161/HYPERTENSIONAHA.107.093336

[4] U.S. National Heart, Lung and Blood Institute (2006) Your Guide to Lowering Your Blood Pressure with DASH, No. 06-5834.

[5] Stigler, G. (1945) The Cost of Subsistence. Journal of Farm Economics, 25, 303-314. http://dx.doi.org/10.2307/1231810

[6] Smith, V.E. (1959) Linear Programming Models for the Determination of Palatable Human Diet. Journal of Farm Economics, 41, 272-283. http://dx.doi.org/10.2307/1235154

[7] Fletcher, L.R., Soden, P.M. and Zinober, A.S.I. (1994) Linear Programming Techniques for the Construction of Palatable Human Diets. Journal of the Operational Research Society, 45, 489-496. http://dx.doi.org/10.1057/jors.1994.76

[8] Mamat, M., Zulkifli, N.F., Deraman, S.K. and Noor, N.M.M. (2012) Fuzzy Linear Programming Approach in Balance Diet Planning for Eating Disorder and Disease-Related Lifestyle. Applied Mathematical Sciences, 6, 5109-5118. 


\section{Appendix}

Formulated mathematical model for 2000 calorie a day eating plan

$$
\text { Minimize } D C=15 X_{1}+20 X_{2}+15 X_{3}+15 X_{4}+30 X_{5}+15 X_{6}+15 X_{7}+50 X_{8}
$$

subject to the constraints

$$
0.24 X_{1}+11.48 X_{2}+0.58 X_{3}+0.30 X_{4}+0.10 X_{5}+0.48 X_{6}+0.16 X_{7}+4.1 X_{8} \leq 68
$$

(constraint on total fat)

$$
33.60 X_{1}+1.5 X_{2}+124.8 X_{3}+15 X_{4}+8.1 X_{5}+3.2 X_{6}+2.4 X_{7}+73 X_{8} \leq 1500
$$

(constraint on sodium)

$$
0 X_{1}+0 X_{2}+0 X_{3}+0 X_{4}+3 X_{5}+0 X_{6}+0 X_{7}+0.29 X_{8} \leq 129
$$

(constraint on cholesterol)

$$
0 X_{1}+1.55 X_{2}+0.2 X_{3}+0 X_{4}+0.6 X_{5}+0 X_{6}+0 X_{7}+340 X_{8} \leq 16
$$

(constraint on saturated fat)

$$
28 X_{1}+4.25 X_{2}+12.25 X_{3}+24 X_{4}+250 X_{5}+49.6 X_{6}+5.6 X_{7}+40 X_{8} \geq 1334
$$

(constraint on calcium)

$$
9.6 X_{1}+47.75 X_{2}+13.25 X_{3}+14 X_{4}+2.4 X_{5}+17.6 X_{6}+8 X_{7}+43 X_{8} \geq 542
$$

(constraint on magnesium)

$$
2.48 X_{1}+2.33 X_{2}+1.55 X_{3}+3 X_{4}+0 X_{5}+2.72 X_{6}+0.24 X_{7}+0 X_{8} \geq 34
$$

(constraint on fibre)

$$
\text { 212.8 } X_{1}+181.75 X_{2}+56.5 X_{3}+264 X_{4}+31 X_{5}+262.6 X_{6}+87.2 X_{7}+397 X_{8} \geq 4721
$$

(constraint on potassium)

$$
20 X_{1}+144.5 X_{2}+58.5 X_{3}+90 X_{4}+7 X_{5}+72 X_{6}+23.2 X_{7}+151 X_{8}=2000
$$

(constraint on calorie)

$$
\begin{aligned}
& X_{1} \geq 4 \\
& X_{2} \leq 1 \\
& X_{3} \geq 3 \\
& X_{4} \geq 4 \\
& X_{5} \geq 6 \\
& X_{6} \geq 4 \\
& X_{7} \geq 4 \\
& X_{8} \leq 6 \\
& X_{1} \leq 20 \\
& X_{3} \leq 8 \\
& X_{4} \leq 6 \\
& X_{5} \leq 9 \\
& X_{6} \leq 8 \\
& X_{7} \leq 9
\end{aligned}
$$


Table A1. Sample foods together with their nutrient composition, weigh (in grams) and cost for a serving size.

\begin{tabular}{|c|c|c|c|c|c|c|c|c|}
\hline \multirow[b]{2}{*}{ Nutrients } & \multicolumn{8}{|c|}{ Foods } \\
\hline & Carrot & $\begin{array}{l}\text { Ground nut } \\
\text { (cooked) }\end{array}$ & $\begin{array}{c}\text { Bread } \\
\text { (whole wheat) }\end{array}$ & $\begin{array}{l}\text { Sweet potato } \\
\text { (boiled) }\end{array}$ & $\begin{array}{c}\text { Milk } \\
\text { (low fat) }\end{array}$ & Orange & $\begin{array}{l}\text { Water } \\
\text { melon }\end{array}$ & $\begin{array}{c}\text { Fish } \\
\text { (grilled) }\end{array}$ \\
\hline Total fat & 0.24 & 11.48 & 0.58 & 0.30 & 0.10 & 0.48 & 0.16 & 4.10 \\
\hline Sodis sodium & 33.60 & 1.50 & 124.80 & 15.00 & 8.10 & 3.20 & 2.40 & 73.00 \\
\hline Sddd cholesterol & 0 & 0 & 0 & 0 & 3.00 & 0 & 0 & 0.29 \\
\hline Saturated fat & 0 & 1.55 & 0.20 & 0 & 0.60 & 0 & 0 & 34.00 \\
\hline Calcium & 28.00 & 4.25 & 12.25 & 24.00 & 25.00 & 49.60 & 5.60 & 40.00 \\
\hline Magnesium & 9.60 & 47.75 & 13.25 & 14.00 & 2.40 & 17.60 & 8.00 & 43.00 \\
\hline Fiber & 2.48 & 2.33 & 1.55 & 3.00 & 0 & 2.72 & 0.29 & 0.00 \\
\hline Potassium & 212.8 & 181.75 & 56.50 & 264.0 & 31.0 & 265.6 & 87.2 & 549.0 \\
\hline Calorie & 28 & 144.50 & 58.5 & 90.00 & 7.00 & 72.0 & 23.2 & 151.00 \\
\hline $\begin{array}{l}\text { Weight per serving of food } \\
\text { (in grams) }\end{array}$ & $80 \mathrm{~g}$ & $25 \mathrm{~g}$ & $25 \mathrm{~g}$ & $100 \mathrm{~g}$ & $20 \mathrm{~g}$ & $160 \mathrm{~g}$ & $80 \mathrm{~g}$ & $100 \mathrm{~g}$ \\
\hline Cost of per serving of food & N15 & N20 & N15 & N15 & N30 & N15 & N15 & N50 \\
\hline
\end{tabular}

Table A2. DASH daily calorie need chart for different level of activities.

\begin{tabular}{|c|c|c|c|c|}
\hline \multirow{2}{*}{ Gender } & \multirow{2}{*}{ Age } & \multicolumn{3}{|c|}{ Calories needed for each activity level } \\
\hline & & Sedentary & Moderately active & Active \\
\hline \multirow{3}{*}{ Female } & $19-30$ & 2000 & $2000-2200$ & 2400 \\
\hline & $31-50$ & 1800 & 2000 & 2200 \\
\hline & $51+$ & 1600 & 1800 & $2000-2200$ \\
\hline \multirow{3}{*}{ Male } & $19-30$ & 2400 & $2600-2800$ & 3000 \\
\hline & $31-50$ & 2200 & $2400-2600$ & $2800-3000$ \\
\hline & $51+$ & 2000 & $2200-2400$ & $2400-2800$ \\
\hline
\end{tabular}

Table A1 showing sample foods together with their nutrient composition, weigh (in grams) and cost for a serving size. 